\title{
Evaluation of Doctor-patient communication outcomes in two public hospitals in Enugu and Ebonyi States, Nigeria
}

\author{
Michael O. Ukonu, Chidiebere A. Nwachukwu \\ \&Olanrewaju A. Mgboji \\ Department of Mass Communication, University of Nigeria, \\ Nsukka \\ Email: chidiebere.nwachukwu@unn.edu.ng
}

\begin{abstract}
Background: Patient-doctor communication is a critical success factor in ensuring accurate diagnosis and treatment. A patient's satisfaction with such interaction can have positive impact on health outcomes. This study evaluated patient-doctor communication in two tertiary hospitals in two states in southeast Nigeria.

Data Source \& Methods: Data were collected with a structured questionnaire from 300 patients in two teaching hospitals. Data were analysed using simple percentages, chi-square test of independence, binary logistic regression and factor analysis.

Results: Results indicated low level of satisfaction of patients with the quality of communication with their doctors, the main contributor to their dissatisfaction being 'doctors' authoritarian communication style'. Factors that positively predicted patients' satisfaction were 'doctors' communication skills' $(p=.000)$, 'patients' religious, cultural and language anxiety influence on communication' $(p=.000)$, and 'democratic communication' $(p=.009)$. Doctors adopted the paternalistic approach in interacting with patients.
\end{abstract}

Conclusion: Patients reported low level of satisfaction with their doctors' communicative behaviour. This would necessitate a shift from the paternalistic to the patient-centred communication approach in the two hospitals.

Keywords: Communication, patient satisfaction, health outcomes, hospitals, doctors

\section{Introduction}

Ordinarily, immediately preceding the onset of an illness should be consultation with a physician or health expert for possible cure. On the contrary, many sick people make prior consultations with friends, family, acquaintances, herbal healers, and spiritual doctors. The medical doctor can become the last option, and in many cases, Nigerians believe it is out-of-hand cases that should go to the doctor (Anker, Reinhart, and Feeley, 20II).

Similarly, many patients see doctors as super humans, and some form of trepidation attends consultation with doctors. Some sick people are only satisfied with seeing a doctor. They neither truly express themselves nor understand the doctor (Baker, 2010). When patients complain about the persistence of an illness even after going to hospital, the problem may lie with communication. Patients' worries also heighten because of certain hospital processes, which many patients consider unsettling, including the involvement of many other medical personnel (nurses, relatives, administrative staff, etc.) before a patient finally sees the doctor (Abiola,Udofia and Abdullahi, 20/4). It is for this reason that patientdoctor communications have continued to attract the attention of research in health communication.

This study attempts to ascertain the influence of patient-doctor communication on patient satisfaction leading to health outcomes; approaches employed to guide such communication and the intervening variables that impinge on the quality and outcome of such communication. In the Nigerian setting, particularly, there are many intervening variables that impinge on healthcare delivery, which studies have yet to consider in the context of patient-doctor communication outcomes. Some of them are stereotypes about doctors, wilful non-disclosure due to fear of cost of treatment, differences in communication settings in private and public hospitals, notions received from self-diagnosis, influences of friends and family and information from alternative sources of healthcare such as herbal healers.

Some studies have used these variables on their own or in general assessment of patient evaluation of healthcare, but not on patient-doctor communication outcomes (Abiola, Udofia and Abdullahi, 2014; 
Mohammed, Idowu, Kuyinu, 2010). It should be noted that Agenda 2063 of the African Union, in articles 53 and 57, shows commitment in removing all barriers to quality health services to citizens.

Additionally, Nigerian hospitals are noted for facility problems, which may be a starting point of patient evaluations and expectations. A study on primary health care in rural Lagos indicated that $78 \%$ of health centres had inadequate supply of water, electricity and poor toilet facilities; there were deficiencies in basic equipment, ambulance services, and physical access to facilities (Mohammed, Idowu, and Kuyinu, 2010; Ogaji, Giles, Daker-White and Bower, 2016). In line with the views of Juran and Gryna (1993), the level of congruency in the expectations of patients and processes in healthcare as well as hospital staff attitudes prior to seeing the doctor often have significant impacts on healthcare outcomes. Similarly, patients' socio-demographic attributes and system attributes greatly influence patient-reported experiences on health care (Lewis, 1994, cited in Ogaji, Giles, Daker-White and Bower, 2016).

\section{Literature review}

Patient satisfaction and health outcomes

Usually, the initial influence of doctor's interaction with a patient is the assurance in the patient that recovery may or may not be imminent. Such communication can therefore become the first therapy towards full recovery and psychological balance. As noted by ledema and Manidis (2013), effective communication heals, while sub-standard communication may have negative effects. Researchers are agreed that patient-doctor communications can have significant therapeutic effects (Travaline, Ruchinskas and D'Alonzo 2005; Fong \&Longnecker 2010,Brédart, Bouleuc\&Dolbeault 2005, Moore, Vargas, Núñez\&Macchiavello 201I, Anthony, Berman, Darry \&Chutka 2016).

Patient-doctor communication can also build a relationship that helps patients to live better life after recovery (Brédart, Bouleuc and Dolbeault, 2005). When such interactions go wrong, they can lead to misdiagnosis and wrong treatments, and can become issues in medical malpractice lawsuits (Moore, Vargas, Núñez and Macchiavello, 20I I).

Al-Abri and Al-Balushi (20l4) define patient satisfaction as the level of agreement between patients' notions about ideal care and their perceptions of the care received. The authors believe that future communication and health behaviours towards doctors and doctors' prescriptions depend significantly on patient satisfaction. Therefore, when patients have a favourable perception of healthcare provision, there is said to be patient satisfaction.
Patients need to be satisfied with the clinical procedure because such satisfaction is in itself a central variable in measuring healthcare delivery and health outcomes (Powell, 20I I; Murante, 20I0; AlAbri\& Al-Balushi, 20I4; Andrabi, Hamid, Rohul\&Anjum, 20I2).

Patient satisfaction is often attended by positive health outcomes, which entails deducible changes in health after medical attention (King and Hoppe, 20I3). Flocke, Miller and Crabtree (2002) did a cross sectional study looking at $288 \mathrm{I}$ patient visits of I 38 family doctors and categorised physicians' interaction styles into four categories: person-focused, biopsychosocial, biomedical and high physician control by the use of a primary care instrument. The study indicated that physicians with a person-focused interaction style with patients were associated with the highest reported quality of care by patients, while physicians with high control styles were associated with the lowest reported quality of care. Similarly, Kelley, Kraft-Todd, Schapira, Kossowsky and Riess, (20/4) demonstrated that patient-clinician relationship has a small, but statistically significant effect on healthcare outcomes.

\section{Approaches and models of patient-doctor communication}

Doctors use different approaches in discussing with patients. This study considers two broad approaches, namely, patient-centred approach and paternalistic approach. Roter (20I0) defines patient-centeredness as a biopsychosocial approach to medical treatment that upholds patients' preferences, experiences and expectations, with the patient having ample opportunity to contribute in the healthcare they receive in a mode that promotes partnership and understanding.

Researchers have attested to the potency of the patient-centred approach in health service delivery (Wynia and Matiasek, 2006); Frosch, May, Rendle, TietbohlElwyn, 2012; Frampton, Charmel, Guastello, 2013 \&Guastello, 20I4; Roter 20I0). King and Hoppe (20I3), for instance, found that good patient-centred communication is associated with patient recall, patient understanding and patient adherence to therapy.

In patient-centred approach, the major goal is to get care givers to expand upon the biomedical approach to communicate with the patient. This approach, which is based on moral philosophy, implies (I) helping patients feel understood through inquiry into patients' needs, perspectives and expectations; (2) attending to the psychosocial context; and (3) expanding patients' involvement in understanding their illnesses and in decisions that affect their health (Epstein, Franks, Shields, Meldrum, 
Miller, Campbell, and Kevin, 2005; LeBlan, 20I5; The paternalistic approach is basically doctorcentred. The approach puts the entire burden of communication and health decisions on the doctor in much the same way parents dictate to their children in key decisions (Roter, 2010; Hellin, 2002). The paternalistic approach is seen as hard-line approach where the doctor has the autonomy of decisions and expects submissiveness from the patient (Kapa and Sooriakumaran, 2007; Murgic, Hébert Sovic, and Pavlekovic, 2015).

Roter (2010) looks at the relationship as a therapeutic visit whose procedure and outcome depend on the approach used. The model talks about the goals of the visit, patient values and physician roles. When the approach is paternalistic, the doctor determines the goal of the visit, presumes patient values and takes the role of a guardian. The process can also be based on mutuality in which goals of the visit are negotiated, patient values are explored and the doctor becomes an advisor. If it is based on consumerism, the visit yields technical information, patient values are unexamined and the doctor becomes a consultant.

Citing Chanin (nd), Wilkins (2014) warns doctors against thinking only in terms of what the patient needs, and also consider how the patient will consider what the doctor is prescribing. Wilkins believes that there is nothing doctors can do and that prescriptions will be of no effect if the patient refuses to adhere to them. Therefore, the ultimate aim should be to assure patient satisfaction and accession to doctor's prescriptions.

\section{Intervening variables in doctor-patient communication}

It is not enough to simply outline the benefits of patient-doctor communication and the approaches to it. Research evidence suggests that there are intervening variables that influence the outcomes of patient-doctor communications such as culture, education, gender, economic status and religion. (Ademola and Okunola, 2013; Maraña 20I0; Zadeh and Mozaffari, 20I4).

A study in Egypt found that gender was a factor in whether women would discuss sexual matters with male doctors (Eltony, Saboula and Hussein, 20/3). Taylor, Nicolle and Maguire (20/3) reported in a study in the United Kingdom that access to healthcare could be lost when some, particularly Muslims, refuse to allow a female patient to be examined by a male doctor and even a son would not discuss his mother's condition with a female doctor. Bertakis, Franks and Epstein (2009) in a study of 100 family physicians and internists with clinical practices in the Rochester, New York area, reported that
Dean and Street 2014).

patients' gender can affect the interactions between physicians and patients. Religion also plays a vital role in what patients tell their doctors and is seen as an aspect of wellbeing (Bradshaw and Ellison, 2010; Pargament and Saunders, 2007).

On economic status, Gao, Burke, Somkin and Pasick (2009) developed what they called power distance in cultural and social relations. They used terms such as low power distance and high power distance, in which emphasis is placed on how people of various statuses relate. When one party in a relationship considers another party as highly-rated, there is said to be high power distance. In Nigeria (where there is high power distance) the average patient sees the doctor as all-knowing, and this usually affects patient confidence level, the quality and extent of communication due to cultures of inequality, coercive power and dependent relationships of subordinates on superiors.

In the US, Canada, and the UK, where there is low power distance, emphasis is placed on equality, legitimate power and interdependent relationships between superiors and subordinates (Gao, et al, 2009). In a study on determinants of postnatal care use in Kenya, Akunga, Menya and Kabue (2014) found that only $40 \%$ of the women had been informed of the signs of pregnancy complications during antenatal care visits. Majority of the women (about 90\%) had at least primary education. This suggests that there might have been high power distance between the women and the midwives, and this may have accounted for the communication gap.

Closely related to this is education and health literacy. Patients with high education and high health literacy are more likely to have more satisfactory communication with their doctors than otherwise (Kai, Beavan and Faull, 20II, cited in Cerimagic, 2013). Kilbridge, Fraser, Krahn, Nelson, Conaway, and Bashore (2009) studied African-American patients who used low-income clinics in the US. They found that fewer than $50 \%$ of patients understood the terms "erection" or "impotent." Only 5\% of patients understood the term "incontinence" and $25 \%$ understood the term "bowel habits." More patients recognized word roots than related terms or compound words (eg, "rectum" vs "rectal urgency," "intercourse" vs "vaginal intercourse").

In the present study, personal interaction with patients during the pre-testing of the questionnaire revealed further contexts within which doctorpatient interactions can be examined, but which have not been taken into account in several studies. Such contexts include the influences of alternative sources of health information (friends for instance), patient's own self-diagnosis, type of hospital and fear of being 
diagnosed with terminal illness. These were incorporated into the study.

\section{Data and methods}

Data for the study were collected from 300 outpatients in two federal tertiary hospitals: The Federal Teaching Hospital, Abakaliki, Ebonyi State and The University of Nigeria Teaching Hospital (UNTH), Enugu. Since the study involved an infinite population, the sample size of 300 was arrived at through Comrey and Lee's (1992, cited in Wimmer and Dominick, 20II:103) formula: 50=very poor; $100=$ poor; $200=$ fair; $300=$ good; $500=$ very good; $1000=$ excellent.

The teaching hospitals are assumed to be the best equipped and staffed in the country, and while located in the cities, they cater to both urban and rural residents as well as those in the upper, middle and lower income quintiles. In addition, other hospitals usually refer patients to the teaching hospitals for more serious diseases.

After approvals by the hospital ethics committees, participants were approached at the out-patient units of the hospitals and their consent to participate in the study secured. Patients were considered eligible for the study if they had attended appointments with their doctor at least two times in the last three months prior to the study. This was to make sure that participants could evaluate communication with physicians from a position of knowledge.

The content of communication between the patient and doctor, which is of interest to the study includes statements and questions from the doctor and responses from the patient on the health condition of the patient. This normally includes exchange of pleasantries, initial questions about what the patient suffers from, responses from the patient, follow-up questions from the doctor, doctor's gesticulations, ways of cutting into responses from the patient, assurances from the doctor about cure, and patient feelings about communication experience.

The instrument used for data collection was a 28item, five point Likert scale questionnaire, which addressed two independent variables: doctors' communication behaviour and factors that impinge on doctor-patient communication. The dependent/outcome variable was patients' level of satisfaction. The doctors' communication behaviour was used to assess the dominant communication approach (paternalistic or patient-centred model) adopted by the doctors in their interactions with patients. The participants' responses were grouped into 'to a very low extent,' 'to a low extent,' 'to a moderate extent,' 'to a large extent,' and 'to a very large extent.'

Socio-demographic explanatory variables used included age (I8-30; 3I-40; 4I-50; $5 I$ and above); gender (male and female); marital status (never married, married, divorced and widowed); education (no academic qualification, primary, secondary and tertiary); income level (below 18,000; 18,000-30,000; $31,000-45,000 \quad 46,000-60,000 ; 61,000-70,000$ and above 7I,000); denomination (Catholic, nonCatholic, non-Christian) and hospital (Federal Teaching Hospital, Abakaliki and University of Nigeria Teaching Hospital, Enugu.).

Descriptive and inferential statistics were used in the analysis of data for this study. Among the descriptive statistics, simple percentages and frequency counts were used, while among the inferential statistics, chi-square test of independence and factor analysis were used. All analyses were done with the use of the Statistical Package for the Social Sciences (SPSS) version 23.

Factor analysis also was used to assess factors affecting patient-doctor communication in the two hospitals. This was achieved in three steps (assessment of data, factor extraction and factor rotation). First, we investigated the correlation matrix for coefficients of . 3 and above, and calculating the Kaiser-Meyer-Olkin Measure of Sampling Adequacy (KMO) and Bartlett's Test of Sphericity. The second step involved determining how many underlying factors could be found in the set of variables under investigation. Eigen value greaterthan-one criterion, scree plot interpretation and interpretability of the factor structure were employed to find the most suitable components for the variables that were investigated. Finally, Varimax rotation and Oblimin rotation were further used to determine how strongly inter-correlated the factors were.

The specific objectives of the study were to:

a. Ascertain the level of patient satisfaction after communication with the doctor

b. Examine the influence of demographic factors on patient-doctor communication outcomes.

c. Identify a set of factors that represents the underlying relationships among a group of variables which affects patient-doctor communication in two hospitals. 
Results

\begin{tabular}{lll}
\hline Table 1: Socio-demographic & Attributes of Respondents \\
\hline Variables & Frequency & Percentage \\
Sex & 123 & 47 \\
Female & 137 & 53 \\
Male & & \\
Age & 25 & 10 \\
$18-30$ & 117 & 45 \\
$31-40$ & 42 & 16 \\
$41-50$ & 76 & 29 \\
51 and above & & \\
Marital Status & 41 & 16 \\
Never married & 185 & 71 \\
Married & 16 & 6 \\
Divorced & 18 & 7 \\
Widowed & & \\
Educational Level & 19 & 7 \\
No formal education & 17 & 7 \\
Primary Education & 75 & 29 \\
Secondary Education & 149 & 57 \\
Tertiary Education & & \\
Income Level & 113 & 44 \\
N18,000-30,000 & 37 & 14 \\
31,000-45,000 & 26 & 10 \\
46,000-60,000 & 60 & 23 \\
61,000-70,000 & 24 & 9 \\
7,000 and above & & \\
Religious Affiliation & 162 & 62 \\
Catholic & 35 & 14 \\
Non Catholic & 63 & 24 \\
Non Christian & & \\
\hline & &
\end{tabular}

Out of the 300 respondents, a total of 260 copies of the questionnaire (I22 and 138 for FETHA and UNTH respectively) were retrieved and used for analysis. The result from Table I showed that there were slightly more male respondents than female respondents. Most of the respondents were within the age range of $31-40$ years and most of them were married. In particular, the number of married respondents was more than half of the overall sample. More than half of the respondents reported having tertiary education. Most of the respondents reported an income level of $61-70,000$ per month. 
Level of patient satisfaction after communication with the doctor

Table 2: Patient Satisfaction

\begin{tabular}{|c|c|c|c|c|c|}
\hline & & & \multicolumn{2}{|c|}{ HOSPITAL } & \\
\hline \multirow{7}{*}{$\begin{array}{l}\text { I felt satisfied after talking } \\
\text { with the doctor }\end{array}$} & & & UNTH & FTHA & Total \\
\hline & To a very low extent & Count & 26 & 74 & 100 \\
\hline & & $\%$ within hospital & $34.7 \%$ & $38.7 \%$ & $37.6 \%$ \\
\hline & To a low extent & Count & $29_{3}$ & & 86 \\
\hline & To a moderate extent & $\begin{array}{l}\% \text { within hospital } \\
\text { Count } \\
\% \text { within hospital }\end{array}$ & $\begin{array}{l}38.7 \% \\
17 \\
22.7 \%\end{array}$ & $\begin{array}{l}29.8 \% \\
31, \\
19.4 \%\end{array}$ & $\begin{array}{l}32.3 \% \\
48 \\
20.3 \%\end{array}$ \\
\hline & To a large extent & $\begin{array}{l}\text { Count } \\
\% \text { within hospital }\end{array}$ & $\begin{array}{l}2 \mathrm{a} \\
2.7 \%\end{array}$ & $\begin{array}{l}18 \mathrm{a} \\
9.4 \%\end{array}$ & $\begin{array}{l}20 \\
7.5 \%\end{array}$ \\
\hline & To a very large extent & $\begin{array}{l}\text { Count } \\
\% \text { within hospital }\end{array}$ & $\begin{array}{l}1, \\
1.3 \%\end{array}$ & $\begin{array}{l}5, \\
2.6 \%\end{array}$ & $\begin{array}{l}6 \\
2.3 \%\end{array}$ \\
\hline \multirow{2}{*}{\multicolumn{2}{|c|}{ Total }} & Count & 75 & 185 & 260 \\
\hline & & $\%$ within hospital & $100.0 \%$ & $100 \%$ & $100 \%$ \\
\hline
\end{tabular}

Each subscript letter denotes a subset of hospital categories whose column proportions do not differ significantly from each other at the .05 level.

Patient assessment of communication outcomes with the doctor

Majority of the patients reported low extent of satisfaction after communicating with the doctor. More patients reported moderate satisfaction relative

to those who reported that they were satisfied to a large extent.

Table 3: Indices of Patient Satisfaction

\begin{tabular}{|c|c|c|c|c|c|}
\hline Communication Factor & $\begin{array}{l}\text { Very low } \\
\text { extent }(\%)\end{array}$ & Low extent & $\begin{array}{l}\text { Moderate } \\
\text { extent }\end{array}$ & $\begin{array}{l}\text { Large } \\
\text { extent }\end{array}$ & $\begin{array}{l}\text { To a very } \\
\text { large } \\
\text { extent }\end{array}$ \\
\hline $\begin{array}{l}\text { The doctor allowed me to } \\
\text { explain myself adequately } \\
n=260\end{array}$ & $73(28.1 \%)$ & $113(43.5 \%)$ & $31(2 \%)$ & $15(5.7 \%)$ & $28(10.7 \%)$ \\
\hline $\begin{array}{l}\text { I would recommend the } \\
\text { same doctor to my friends } \\
n=260\end{array}$ & $84(32.35)$ & $110(42.3 \%)$ & $40(15.3 \%)$ & $12(4.6 \%)$ & $14(5.3 \%)$ \\
\hline $\begin{array}{l}\text { The doctor clearly told me } \\
\text { the nature of my illness } \\
n=260\end{array}$ & $79(30.4 \%)$ & $108(41.5 \%)$ & $49(18.8 \%)$ & $13(5.0 \%)$ & $11(4.2 \%)$ \\
\hline $\begin{array}{l}\text { I felt the doctor was } \\
\text { listening as I talked } n=260\end{array}$ & $85(32.6 \%)$ & $91(35 \%)$ & $55(21.1 \%)$ & $22(8.4 \%)$ & $7(2.7 \%)$ \\
\hline $\begin{array}{l}\text { My questions were } \\
\text { adequately answered } \\
\mathbf{n}=260\end{array}$ & $104(40 \%)$ & $96(37.1 \%)$ & $40(15.4 \%)$ & $15(5.8 \%)$ & $4(1.5 \%)$ \\
\hline $\begin{array}{l}\text { The doctor interrupted me } \\
\text { before I finished } \mathbf{n}=\mathbf{2 5 9}\end{array}$ & $28(10.8 \%)$ & $24(9.3 \%)$ & $50(19.3 \%)$ & $102(39 \%)$ & $55(25.2 \%)$ \\
\hline $\begin{array}{l}\text { I felt the doctor } \\
\text { understood me fully } n=260\end{array}$ & $91(35 \%)$ & $90(34.6 \%)$ & $46(17.6 \%)$ & $27(10.3 \%)$ & $6(2.3 \%)$ \\
\hline $\begin{array}{l}\text { I felt relaxed in the } \\
\text { doctor's presence } n=260\end{array}$ & $94(36.1 \%)$ & $102(39.2 \%)$ & $27(10.3 \%)$ & $16(6.1 \%)$ & $21(8.0 \%)$ \\
\hline $\begin{array}{l}\text { The doctor appeared } \\
\text { impatient } n=256\end{array}$ & $32(12.5 \%)$ & $44(17.2 \%)$ & $38(14.8 \%)$ & $87(34.0 \%)$ & $55(21.5 \%)$ \\
\hline $\begin{array}{l}\text { The doctor treated me } \\
\text { with respect } n=260\end{array}$ & $111(42.7 \%)$ & $80(30.8 \%)$ & $37(14.2 \%)$ & $25(9.6 \%)$ & $7(2.7 \%)$ \\
\hline $\begin{array}{l}\text { The doctor frightened me } \\
\text { more about my illness } \\
\text { n=249 }\end{array}$ & $22(8,8 \%)$ & $21(8.4 \%)$ & $64(25.7 \%)$ & $86(34.5 \%)$ & $56(22.5 \%)$ \\
\hline
\end{tabular}


In line with the general level of satisfaction reported by patients, low extent of satisfaction was reported on all the indices expressing assessment of communication with the doctor. This indicated that patients did not feel that communication approach used was in their favour. There was very low likelihood that it was patient-centred.

Influence of socio-demographic factors on the patients' level of satisfaction

The influence of demographic factors on the patients' level of satisfaction was ascertained using binary logistic regression. The level of satisfaction variable was transformed into two categories of 'satisfied' and 'not satisfied'. This was done by first obtaining the average response of each respondent on the variable. Any average response less than 3.0 is considered 'not satisfied' while any average response from 3.0 and above is considered 'satisfied. Then, 'not satisfied' was coded ' 0 ' (zero) while 'satisfied was coded ' $I$ ' (one) to convert the variable to binary. The demographic variables which are the predictor variables include age, gender, marital status, educational level, income level and religious denomination. The outcomes of the logistic regression analysis are summarized in Table 4.

Table 4: Demographic Predictors of Patients' Level of Satisfaction

\begin{tabular}{llllll}
\hline $\begin{array}{l}\text { DEMOGRAPHIC } \\
\text { PREDICTORS }\end{array}$ & B & S.E. & Wald & df & Sig. \\
\hline Age & 1.196 & .316 & 14.330 & 1 & .000 \\
Gender & 1.400 & .618 & 5.135 & 1 & .023 \\
Marital Status & -687 & .340 & 4.095 & 1 & .043 \\
Educational Level & -136 & .289 & .221 & 1 & .638 \\
Level of Income & 1.136 & .406 & 7.816 & 1 & .005 \\
Religious Affiliation & .442 & .499 & .786 & 1 & .375 \\
Constant & -8.324 & 1.586 & 27.544 & 1 & .000 \\
\hline
\end{tabular}

A multiple regression was calculated to predict the level of satisfaction of the patients at both hospitals. The results of the regression indicated that the model explained $49.0 \%$ of the variance $F(6,263)=12.17$, $(p=.000)$. While patients' age $(p=0.000)$, gender $(p=0.023)$, marital status $(p=0.43)$ and level of income $(p=0.005)$ contributed significantly to the model, educational level $(p=0.638)$ and religious denomination $(p=0.375)$ did not make any significant contribution. Specifically, age $(b=1.196)$ positively predicted patients' level of satisfaction, suggesting that the higher the age category of respondents, the more likely they were to be satisfied in their patientdoctor communication. In other words, respondents who were from 50 years and above were likely to have the highest scores on patients' level of satisfaction. Gender $(b=1.400)$ was also found to have positively predicted patients' level of satisfaction. Further observation of the data suggests that high scores on patients' level of satisfaction were found among males than females. Patients' income level $(b=I .136)$ also positively influenced their level of satisfaction, with patients who have high income having higher levels of satisfaction. However, marital status $(b=-.687)$ negatively predicted patients' level of satisfaction. Further observation of the data showed that there were more married patients who scored lowest in their level of satisfaction than patients who were never married, divorced and widowed. 
Table 5: Communication Outcomes based on Individual-level Attributes

\begin{tabular}{llllll}
\hline Communication Factor & $\begin{array}{l}\text { Very low } \\
\text { extent(\%) }\end{array}$ & Low extent & $\begin{array}{l}\text { Moderate } \\
\text { extent }\end{array}$ & $\begin{array}{l}\text { Large } \\
\text { Extent }\end{array}$ & $\begin{array}{l}\text { To a very } \\
\text { large extent }\end{array}$ \\
\hline $\begin{array}{l}\text { I prefer being examined by } \\
\text { male doctor n=249 }\end{array}$ & $59(23.6)$ & $22(8.4 \%)$ & $36(14.5)$ & $83(33.3 \%)$ & $22(8.8)$ \\
$\begin{array}{l}\text { I prefer being examined by } \\
\text { female doctor n=260 }\end{array}$ & $43(16.5 \%)$ & $54(20.7 \%)$ & $64(24.6 \%)$ & $73(28 \%)$ & $26(10 \%)$ \\
$\begin{array}{l}\text { I am uncomfortable when } \\
\text { being examined by a doctor }\end{array}$ & $41(15.7 \%)$ & $43(16.5 \%)$ & $66(25.3 \%)$ & $59(22.6)$ & $51(19.6 \%)$ \\
n=260 & & & & & \\
$\begin{array}{l}\text { I feel less free to discuss my } \\
\text { health with doctors of the } \\
\text { opposite sex n= }\end{array}$ & $25(9.6 \%)$ & $24(9.2 \%)$ & $33(12.6 \%)$ & $88(33.8 \%)$ & $90(34.6 \%)$ \\
$\begin{array}{l}\text { My religion forbids me from } \\
\text { being touched by doctors of } \\
\text { the opposite sex n=260 }\end{array}$ & $20(7.6 \%)$ & $19(7.3 \%)$ & $46(17.6 \%)$ & $73(28.0 \%)$ & $102(39.2 \%)$ \\
$\begin{array}{l}\text { My culture forbids me from } \\
\text { being touched by doctors of } \\
\text { the opposite sex n=260 }\end{array}$ & $23(8.8 \%)$ & $20(7.6 \%)$ & $48(18.4 \%)$ & $67(35.7 \%)$ & $102(39.2 \%)$ \\
$\begin{array}{l}\text { I prefer using my local } \\
\text { language to English when } \\
\text { interacting with the doctor }\end{array}$ & $33(12.6 \%)$ & $53(20.3 \%)$ & $50(19.2 \%)$ & $62(23.8 \%)$ & $62(23.8 \%)$ \\
n=260 & & & & & \\
$\begin{array}{l}\text { I prefer using English while } \\
\text { interacting with the doctor } \\
\text { n=251 }\end{array}$ & $67(25.7 \%)$ & $43(16.5 \%)$ & $69(26.5 \%)$ & $44(16.9 \%)$ & $28(10.7 \%)$ \\
$\begin{array}{l}\text { Did your doctor speak in a } \\
\text { language you understood } \\
\text { n=254 }\end{array}$ & $105(41.3$ & $63(24.8 \%)$ & $53(20.8 \%)$ & $20(7.9 \%)$ & $13(5.1 \%)$ \\
$\begin{array}{l}\text { Fear of threatening diagnosis } \\
\text { made me hide some } \\
\text { information n=259 }\end{array}$ & $34(13.1 \%)$ & $37(14.2 \%)$ & $57(22.0 \%)$ & $71(27.4 \%)$ & $60(23.1 \%)$ \\
$\begin{array}{l}\text { The doctor frightened me } \\
\text { more about my illness n=260 }\end{array}$ & $22(8.4 \%)$ & $21(8.0 \%)$ & $69(26.5 \%)$ & $92(35.3 \%)$ & $56(21.5 \%)$ \\
\hline
\end{tabular}

Majority of the respondents preferred being treated by a male doctor. A far greater number would want a male doctor to a moderate or high extent. This indicated that male and female respondents would prefer a male doctor to a female doctor. Preference of doctors did not coincide with level of comfort when being examined by a doctor. Majority of respondents reported being uncomfortable, to a moderate or high extent, when being examined by a doctor.

Factors underlying relationships among a group of variables which affects patient-doctor communication in two hospitals

We used a multivariate technique, Exploratory Factor Analysis (EFA) to identify a set of factors that represents the underlying relationships among a group of variables which affects patient-doctor communication in two hospitals. Furthermore, we subjected the 28 items of the variables affecting http://aps.journals.ac.za patient-doctor communication to principal component analysis (PCA) using SPSS 23. A careful look at the correlation matrix

showed the presence of many coefficients of .3 and above. The Kaiser-Meyer-Olkin value was .66 (see Table 6) surpassing the value recommended (.6) by Kaiser $(1970,1974)$ and the Bartlett's Test of Sphericity (1954) reached statistical significance $(p<.00 \mathrm{I})$, supporting the factorability of the correlation matrix. According to eigen-value-greaterthan-one criterion, a nine factor solution explaining 17.4I7 per cent, II.I28 per cent, 6.579 per cent, 6.33I per cent, 5.979 per cent, 5.220 per cent, 4.829 per cent, 4.186 per cent, and 3.883 per cent appeared to represent most suitably the response structure on the factors influencing patient-doctor communication among patients sampled in the study. The nine factors were: Confidence in doctor's communication skills; patients' religious, cultural and language anxiety influence on communication; 5122 
democratic communication; language barrier to communication and respect; unattractive hospital environment and exhaustion while waiting for the doctor; patients' subjective perception of doctors and information sharing with friends.

Table 6: KMO and Bartlett's Test

\begin{tabular}{lll}
\hline Kaiser-Meyer-Olkin Measure of Sampling Adequacy. & .659 \\
\hline Bartlett's Test of Sphericity & Approx. Chi-Square & 2590.702 \\
& Df & 378 \\
& Sig. & .000 \\
\hline
\end{tabular}

Table 7: Comparison of eigenvalues from principal component analysis $(\mathrm{PCA})$ and the corresponding criterion values obtained from parallel analysis

\begin{tabular}{llll}
\hline Component number & Actual eigenvalue from PCA & $\begin{array}{l}\text { Criterion value from } \\
\text { parallel analysis }\end{array}$ & Decision \\
\hline 1 & 4.877 & 1.6427 & Accept \\
2 & 3.116 & 1.5544 & Accept \\
3 & 1.842 & 1.4867 & Accept \\
4 & 1.773 & 1.4202 & Accept \\
5 & 1.674 & 1.3637 & Accept \\
6 & 1.462 & 1.3166 & Accept \\
7 & 1.352 & 1.2664 & Accept \\
8 & 1.172 & 1.2220 & Reject \\
9 & 1.087 & 1.1796 & Reject \\
\hline
\end{tabular}

However, we determined the actual number of factors to retain using parallel analysis developed by Watkins (2000). The result of parallel analysis supports our decision from the scree plot to retain only seven components out of the nine, with eigenvalue exceeding the corresponding criterion values for a randomly generated data matrix of the same size ( 28 variables $\times 260$ respondents $\times 100$ number of replications). The retained factors were further investigated. In doing this, the seven factors retained were 'rotated' using Varimax rotation and Oblimin rotation, which presented the pattern of loadings in a manner that is easier to interpret. The rotated solution revealed the presence of simple structure (Thurstone, 1947), with the seven components showing a number of strong loadings and all variable loading substantially on six components. The seven component solution explained a total of 57.48 per cent of the variance, with the components I, 2, 3, 4, 5, 6 and 7 contributing 14.37 per cent, 9.53 per cent, 7.88 per cent, 6.86 per cent, 6.65 per cent, 6.57 per cent and 5.62 per cent respectively.

According to information contained in Table 8, factor loadings of the first extracted factor ('patients'confidence in doctor communication skill') revealed an underlying common factors of items related to patients' view of the doctor as a listener and excellent communicator with regards to the reality of what was diagnosed and other medical 
information. The second factor ('patients' religious, cultural and language anxiety influence on communication') had high loadings on all items that specifically involves the influence of religion, culture and language on patients' fear, which subsequently create a gap in doctor-patients communication.

Table 8: Rotated factor solution for factors affecting patient-doctor communication in the two hospitals

\begin{tabular}{|c|c|c|c|c|c|c|c|}
\hline & \multirow{2}{*}{1} & \multirow{2}{*}{2} & \multirow{2}{*}{3} & \multicolumn{3}{|c|}{ Components } & \multirow{2}{*}{7} \\
\hline & & & & 4 & 5 & 6 & \\
\hline The doctor clearly told me & 836 & & & & & & \\
\hline $\begin{array}{l}\text { the nature of my illness } \\
\text { I would recommend the same }\end{array}$ & .831 & & & & & & \\
\hline $\begin{array}{l}\text { doctor to my frieuds } \\
\text { My questious were } \\
\text { adequately auswered }\end{array}$ & .801 & & & & & & \\
\hline I felt that the doctor & .678 & & & 327 & & & \\
\hline $\begin{array}{l}\text { understood me fully } \\
\text { I felt satisfied with the } \\
\text { doctor's explanations }\end{array}$ & .646 & & 306 & -311 & & & \\
\hline $\begin{array}{l}\text { I felt that the doctor was } \\
\text { listening as I talked }\end{array}$ & .656 & & & 359 & & & -367 \\
\hline $\begin{array}{l}\text { I felt relaxed in the doctor's } \\
\text { presence }\end{array}$ & .625 & & .495 & & & & \\
\hline $\begin{array}{l}\text { My culture forbids me from } \\
\text { being touched by the } \\
\text { opposite sex }\end{array}$ & & .720 & & & & & \\
\hline $\begin{array}{l}\text { My religion forbids me from } \\
\text { being touched by the } \\
\text { opposite sex }\end{array}$ & & .656 & & & & & \\
\hline $\begin{array}{l}\text { Fear of threatening diagnosis } \\
\text { made me hide some } \\
\text { Information }\end{array}$ & & .655 & & & & 423 & \\
\hline $\begin{array}{l}\text { The doctor frightened me } \\
\text { more about the nature of my } \\
\text { siclmess }\end{array}$ & & .613 & & & & & \\
\hline $\begin{array}{l}\text { I prefer using my local } \\
\text { language to English while } \\
\text { interacting with my doctor }\end{array}$ & & 497 & & & -.410 & & \\
\hline The doctor allowed me to & & & .723 & & & & \\
\hline $\begin{array}{l}\text { My friends advised me on } \\
\text { what to tell the doctor }\end{array}$ & & & .645 & & & & \\
\hline $\begin{array}{l}\text { I prefer being examined by a } \\
\text { female doctor }\end{array}$ & & & .763 & & & & \\
\hline $\begin{array}{l}\text { The doctor interrupted me } \\
\text { before I finished }\end{array}$ & & & & .628 & & & \\
\hline $\begin{array}{l}\text { I feel less free to discuss my } \\
\text { health vith doctors of the } \\
\text { opposite sex }\end{array}$ & 302 & & & 573 & & & \\
\hline $\begin{array}{l}\text { The doctor appeared } \\
\text { impatient }\end{array}$ & & .445 & & 545 & & & \\
\hline $\begin{array}{l}\text { I feel uncomfortable when I } \\
\text { am being examined }\end{array}$ & & & .462 & 510 & & & \\
\hline $\begin{array}{l}\text { by a doctor } \\
\text { Did your doctor speals in a } \\
\text { language you } \\
\text { understand? }\end{array}$ & & & & & .743 & & \\
\hline
\end{tabular}




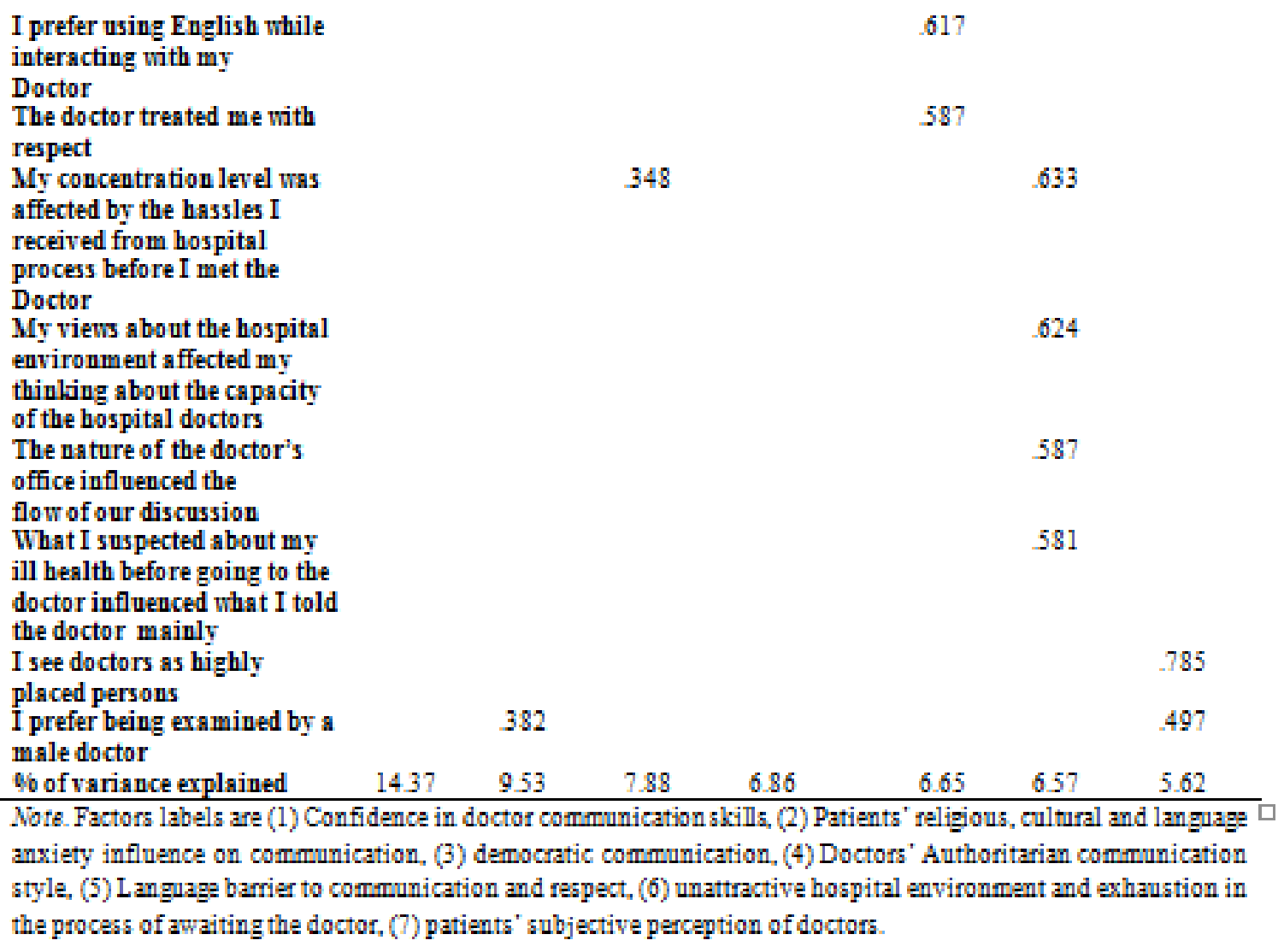

The third factor ('democratic communication') included three high factor loadings that were related to the liberty patients have to communicate freely and make requests on the preferred doctor or physician to communicate with. As to the fourth factor ('doctors' authoritarian communication style), three items referred to the asymmetrical communication between patients and especially male doctors who appear impatient and often interrupt patients during conversations.

The fifth factor ('language barrier to communication and respect') had high loadings on items related to the preferred language spoken by both the doctor and patients as well as how doctors regard the patients. Items relating to the hospital environment, long waiting hours, the doctor's office and fear of a possible diagnosis had the highest loading on the sixth factor ('unattractive hospital environment and exhaustion in the process of awaiting the doctor'). Finally, two items contributed to the seventh factor ('patients' subjective perception of doctors), which related to patients viewing doctors as highly placed and preferring male doctors during examination. In addition, result of an oblique rotation indicated correlations between factors, ranging from $\mathrm{rs}=-0.28$ to $\mathrm{rs}=-0.43$, indicating an interrelatedness between the components. 
Table 9: Summary of a Multiple Regression Analysis for components predicting patients' satisfaction $(\mathrm{N}=\mathbf{2 6 0})$

\begin{tabular}{|c|c|c|c|c|c|c|c|}
\hline \multirow[b]{2}{*}{ Model } & \multicolumn{2}{|c|}{$\begin{array}{l}\text { Unstandardized } \\
\text { Coefficients }\end{array}$} & \multicolumn{2}{|c|}{$\begin{array}{l}\text { Standardized } \\
\text { Coefficients }\end{array}$} & \multicolumn{3}{|c|}{$\begin{array}{l}95.0 \% \text { Confidence Interval } \\
\text { for B }\end{array}$} \\
\hline & B & Std Error & Beta & $\mathbf{T}$ & Sig. & $\begin{array}{l}\text { Lower } \\
\text { Bound }\end{array}$ & $\begin{array}{l}\text { Upper } \\
\text { Bound }\end{array}$ \\
\hline 1. (Constant) & -.584 & .311 & & 1.879 & .061 & -1.196 & .028 \\
\hline Factor 1 & .125 & .009 & .654 & 13.983 & .000 & .107 & .142 \\
\hline Factor 2 & .053 & .011 & .217 & 4.659 & .000 & .031 & .076 \\
\hline Factor 3 & .057 & .021 & .125 & 2.648 & .009 & .015 & .099 \\
\hline Factor 4 & .067 & .014 & -.224 & -4.794 & .000 & -.095 & .040 \\
\hline Factor 5 & .010 & .018 & .025 & .565 & .572 & -.026 & .046 \\
\hline Factor 6 & .011 & .014 & .035 & .815 & .416 & -.016 & .039 \\
\hline \multirow[t]{3}{*}{ Factor 7} & .019 & .022 & .038 & .860 & .391 & -.24 & .061 \\
\hline & $R^{2}$ & & .738 & & & & \\
\hline & $\mathrm{F}$ & & 43.477 & & & & \\
\hline
\end{tabular}

a. Dependent Variable: Patients's satisfaction

Multiple regression analysis was used to test if the factors that were retained in the EFA analysis significantly predicted patients' satisfaction with doctors' communication (Table 9). Every component was appropriately named and transformed into a single score each and was used as a set of the predictor variable in the model. The result of regression analysis indicated that the model explained $74 \%$ of the patients' satisfaction scores $(F(7,262)=43.477, p<.000)$.

A further look at the table showed that while 'confidence in doctor communication skills $(p=.000)$; patients' religion and culture $(p=.000)$; democratic communication $(p=.009)$ and doctors' authoritarian communication style $(p=.000)$ significantly predicted patients' satisfaction level, language barrier to communication and respect $(p=.572)$, unattractive hospital environment and exhaustion in the process of awaiting the doctor $(p=.416)$ and patients' subjective perception of doctors $(p=.391)$ did not contribute to the variances in the model.

In addition, while factors I to 3 were found to have positively predicted the outcome in the model, factor 4 ('doctor's authoritarian communication style) negatively predicted patients' satisfaction. Nonetheless, factors $(5,6 \& 7)$ such as language barrier to communication and respect, unattractive hospital environment and exhaustion in the process of awaiting the doctor and patients' subjective perception of doctors did not significantly predict the outcome in the model.

\section{Discussion}

This study found low level of satisfaction with doctorpatient communication among the respondents. Only http://aps.journals.ac.za
$2.3 \%$ and $7.5 \%$ of the respondents reported being satisfied to a very large extent and to a large extent respectively. The majority $(32.3 \%)$ and $37.6 \%$ reported being satisfied to a very low extent and to a low extent respectively.

Binary logistic regression analysis indicated the influence of demographic factors on patients' level of satisfaction. Age $(p=0.000)$ for instance was found to significantly predict patients' satisfaction with the quality of interaction with their doctors. Specifically, older folks (those above 50) were found to be more likely to have the highest scores on patients' level of satisfaction. This finding is in sync with other studies that found older patients more likely to be satisfied with the quality of their interaction with doctors than younger respondents (Devoe, Wallace and Fryer, 2009; Peck, 20I I).

Moreover, gender $(p=0.023)$ had significant impact on patients' satisfaction, with men more likely to be satisfied relative to female patients. This finding agrees with Jalil, Zakar, Zakar and Fischer (2017) who found that women were more likely to be dissatisfied with doctor-patient communication than men. Gender however, had no influence on patients' preference for doctors as majority of the respondents (men and women) preferred male doctors. This nonetheless, did not affect their satisfaction with their doctor's communication as the majority generally reported being uncomfortable with doctors. This finding is slightly different from other studies (Alyahya, Almohanna, Alyahya, Aldosari, Mathkour, et al, 2019; Nolen, Moore, Rodgers, Wang and Walter, 2016) who found that though the respondents did not have preference with respect to the physicians' gender, in medical examinations 
involving the breasts and genitals, men preferred male doctors and women, female doctors.

Furthermore, economic status was found to have influenced patients' level of satisfaction as those with higher socioeconomic status (SES) reported higher levels of satisfaction. Other studies equally found associations between SES levels and patients' satisfaction levels. Willems, De Maesschalck, Deveugele, Derese and De Maeseneer (2005) and Verlinde, Laender, Maesschack, Deveugele and Willems (20I2) found a link between lower SES and perceptions of being given less socio-emotional talk, more directive and less participatory consulting style and less diagnostic and treatment information. These can all result to patients' dissatisfaction with the physicians' communication. Arpey, Gagliot and Rosenbaum (2017), report that some patients felt that they received poor services from their physicians, and were treated with less respect. They specifically complained of situations in which doctors did not listen to what they were saying or answer their questions because of their socioeconomic status. The ability of people with higher socioeconomic status to enjoy more satisfying interactions with their physicians may be partially explained by the fact that they are likely to be more confident and "communicate more actively and show more effective expressiveness; eliciting more information from their physician"(Willems, et al, 2005).

To further probe the variables that impinge on doctor-patient communication we used Exploratory Factor Analysis to identify a set of seven factors which significantly affect patient-doctor communication in the two hospitals. They include doctors' communication skills; patients' religion and culture; democratic communication; doctors' authoritarian communication style; language barrier to communication and respect; unattractive hospital environment and exhaustion while awaiting the doctor and patients' subjective perception of doctors. The seven factors were further subjected to regression analysis to determine how significantly they predicted patients' satisfaction after interacting with their physicians. The result of the analysis indicated that four factors (confidence in doctor's communication skill; patients' religion and culture; democratic communication and doctor's authoritarian communication style) significantly predicted patients' satisfaction with doctor-patient communication.

Firstly, confidence in the doctor's communication skill $(p=.000)$ was found to positively predict patients' satisfaction. This is consistent with other studies that found a correlation between doctor's communication skills and patients' satisfaction
(Hochman, Itzhak, Mankuta and Vinker, 2008; Rezaei and Askari, 20I4; Biglu, Nateq, Ghojazadeh and Asgharzadeh, 2017).

Furthermore, patients' religion and culture $(p=.000)$ also positively predicted patient's satisfaction following interaction with a physician. Culture affects how a patient perceives diseases and their treatment and, has the capacity to define a patient's relationship with a physician while religion moderates many activities including beliefs about treatment (Paternotte, Dulmen, Lee, Scherphier and Scheele, 20I5). Studies have shown that culture can be a barrier in the doctor-patient communication, making it hard for the patient to establish rapport with doctors and receive sufficient information about their health (Ferguson and Candib, 2002; Paternotte, et al, 2015; Ahmed, Lee, Shommu, Rumana and Turin, 2017).

In addition, analysis showed that while democratic communication $(p=.009)$ positively predicted patient satisfaction, doctors' authoritarian communication style $(p=.000)$ negatively predicted satisfaction. Democratic communication or patient-centred communication is characterised by an open, non restrictive conversation where the doctor encourages the patients to play an active role; converses with them in an intelligible language, shows consideration for their feelings and listens respectfully to their objections and concerns, encouraging them to participate in decision-making. In contrast, autocratic communication style or paternalism is a doctor-centred communication approach in which the doctor dominates the conversation and does not pay much attention to the feelings and concerns of the patient (Bientzle, Fissler, Cress and Kimmerle, 2016; Naughton, 2018; Hashim, 2017). As in this study, some studies (Keller, et al, 20l4; Thomas, Jayakumar and Suyanya, 2017; Levinson, Lesser and Epstein, 20I0; Altin and Stock, 20I6) in other places have linked patient-centred communication with patients' satisfaction.

Doctor's autocratic communication style (paternalism) was associated with patients' dissatisfaction. The communicative behaviours that respondents expressed displeasure with in this study are consistent with paternalism: The doctor not listening to the patients; not allowing them to express themselves adequately; interrupting them before they could finish, etc. While paternalism is frowned at in western medical practice, doctors may not have adopted it out of disrespect for patients. Nigeria is a high power distance nation where the paternalistic approach may come naturally to doctors. Thomas and Whiffen (2018) in their study found that Latino patients were satisfied with the paternalistic approach due to the peculiarities of their culture. However, 
this study shows that patient-centred communication is more likely to produce positive results than paternalistic approach and doctors would do well to put that into consideration.

This study has an inherent weakness, which is the smallness of the sample size used. This weakness limits the generalizability of the results.

\section{Conclusion}

As noted, there was low level satisfaction of patients on almost all the indices measured. This implies a fundamental revisit to patient-doctor communication in the two hospitals. Type of communication, doctors' behaviour during interaction with the patient and patient-feedback systems should be subjects of inquiry in future studies on health communication, health policy, hospital communication systems, health advocacy and communication campaigns. This is in view of the reported influences of type of communication and patients' experiences during interactions with the doctor.

Author Guarantee: We hereby attest that all named authors contributed sufficiently to the work. The study has not been submitted to any other journal for consideration and publication.

\section{References}

Abiola, T., Udofia, O., and Abdullahi, A. (20/4). Patient-doctor Relationship: The Practice Orientation of Doctors in Kano. Nigerian Journal of Clinical Practice, I7(2) pp.24I-247.

Ahmed, S., Lee,S., Shoomu, N., Rumana, N. AND Turin, N. (20I7). Experiences of communication barriers between physicians and immigrant patients: A systematic review and thematic synthesis. Patient Experience Journal, 4(I), 122140

Altin, S.V. and Stock, S. (2016). The impact of health literacy, pstient-centred communication and shared decision-making on patient's satisfaction with care received in German primary care practices. BMC Health Srevices Research, 16, 450

Arpey, N.C., Gagliot, A.H. and Rosenbaum, M.E. (2017). How socio-economic status affect patient perceptions of healthcare A qualitative study. Journal of Primary Care and Community Health, 8(3), I69- I 75.

Bientzle, M., Fissler, T., Cress, U. andKimmerle, J. (2017). The impact of physicians' communication styles on evaluation of physicians and information processing: A randomized study with simulated video consultations on contraception with an intrauterine device. Health Expect, 20(5), pp.84585I
Biglu, M.H., Nateq, F., Ghojazadeh, M. and Asgharzadeh, A. (2017). Communication skills of physicians and patients' satisfaction. Mater Sociomed,29 (3), 192-195

Ademola, E. O. and Okunola, R.A. (20/3). Peoples, Culture and Mass Media as Agent of Cultural Imperialism. Covenant University Journal of Politics and International Affairs (CUJPIA) I (2), pp. 179-191.

Agenda 2063, Popular Version (2015). The Africa We Want. African Union Commission, pp. I-20 (pdf). [Online] Available at https://au.int/en/agenda2063[Accessed 12 January, 2019].

Akunga, A., Menya, D and Kabue, M. (20/4). Determinants of Postnatal Care Use in Kenya. African Population Studies, 28(3), pp. I447-I459.

Alyahya, G., Almohanna, H., Alyahya, A., Aldosari, M., Mathkour,L., Aldhibaib, A., Al-Namshan, Y AND Al-Mousl, N. (20|9). Does physician's gender have any influence on patients' choice of their treating physicians? J Nat Sci Med, 2, 29-34

Andrabi S. A., Hamid S., Rohul, J. \&Anjum F. (20I2). Measuring Patient Satisfaction: A Cross Sectional Study to Improve Quality of Care at a Tertiary Care Hospital, Health Line. 3(I), 59-62.

Anker, A.E., Reinhart, A.M. and Feeley, T.H. (20II), Health Information Seeking: A Review ofMeasures and Methods.Patient Education and Counseling, 82(3), pp.346-54.

Anthony C. Berman and Darryl S. Chutka (2016). Assessing Effective Physician-Patient Communication Skills: "Are You Listening to Me, Doc? Korean Journal of Medical Education 28(2), 243-249.

Bartlett, M. S. (1954). A Note on the Multiplying Factors for Various Chi-Square Approximations. Journal of the Royal Statistical Society, 16 (Series B), 296-298.

Bertakis, K.D, Franks. P, Epstein \& R. M. (2009). Patient-centered Communication in Primary Care: Physician and Patient Gender and Gender Concordance. Journal of Women's Health. 18(4), pp.539-45.

Bradshaw, M., \& Ellison, C. G. (20/0). Financial Hardship and Psychological Distress: Exploring the Buffering Effects of Religion. Social Science and Medicine, 7I, pp. 196-234.

Brédart A, Bouleuc C, Dolbeault S. (2005). Doctorpatient Communication and Satisfaction with Care in Oncology. RevistaMédica de Chile 17(4), Pp.35I-4.

Catell, R. B. (1966). The Scree Test for Number of Factors. Multivariate Behavioral Research, I, 245276. 
Cerimagic, S. (20|3). Cross-cultural Effects on Cancer Patient-Doctor Communication. European Journal of Business and Social Sciences, I(I2), pp. I 92-200.

Dean, $M$ and Street, R. (20I4). A 3-stage Model Of Patient-Centered Communication for Addressing Cancer Patients' Emotional Distress. Patient Education and Counseling. 94 (2), pp. I43-| 48.

Devoe, J.E., Wallace, L.S.and Fryer, G,E. (2009). Patient age influences perceptions about healthcare communication. Family Medicine, $4 I(2), 126$

Eltony, E.M.,Saboula, N.E. and Hussein, A.A. (20/3). Barriers Affecting Utilisation of Family Planning Services among Rural Egyptian Women. Eastern Mediterranean Health Journal, 19(5), pp.400-408.

Eriki, P. Oyo-Ita, A. Odedo, R. Udoh, A. Omaswa, F. and Kadama, P. 2015. Surgical Workforce in Nigeria: Stock and Flow of Medical And Dental Practitioners in Nigeria, With Special Focus on Health Workforce Training in Cross River State. African Centre for Global Health and Social Transformation. [Online] Available at who.int/workforcealliance/031616NigeriaCaseStu dyweb.pdf. [Accessed 2 March, 20I7]

Epstein, R., Franks,P., Shields, C., Meldrum, S.C.,. Miller, K.N., Campbell, T.L. \& Kevin F. (20050. Patient-centered Communication and Diagnostic Testing. Annals of Family Medicine. 3(5), pp.4I5421 .

Ferguson, W.J. and Candib, L.M.(2002). Culture, Language and the doctor-patient relationship. Family Medicine, 34 (5), 353-36I

Flocke SA, Miller WL, Crabtree BF. (2002). Relationships between Physician Practice, Style, Patient Satisfaction, and Attributes of Primary Care. Journal of Family Practice 51, pp.835-40.

Fong, J. \&Longnecker, N (2010). Doctor-patient Communication: A Review. Ochsner Journal I0(I), pp.38-43.

Fowler, J. (2009). Cultural and Structural Barriers that Affect the Doctor-Patient Relationship: A Bolivian perspective. [Online] Available at https://ir.library.oregonstate.edu/xmlui/bitstream/ handle/1957/9896/Fowler.pdf. Accessed 2 March, 2017].

Frampton SB, Charmel, PA, and Guastello S. (20/3). Putting Patients First: Field Guide Global Lessons in Designing and Implementing Patient-Centered Care. San Francisco: Jossey-Bass.

Frosch DL, May SG, Rendle KA, Tietbohl C, Elwyn G. (20I2). Authoritarian Physicians And Patients Fear Of Being Labeled "Difficult" among Key Obstacles to Shared Decision Making. Health Affairs, 3I(5), pp. I030-38.
Gao, G., Burke, N., Somkin, C. \&Pasick, R. (2009). Considering Culture in Physician-Patient Communication during Colorectal Cancer Screening. Qual. Health Res 19(6), pp.778-789.

Gasparik, A.I. and Vasssa, L. (20|4). Relation of some communication parameters to patients' education, gender and age. Teaching to communicate effectively. Social and Behavioural Sciences, 142 (20I4), 367-369.

Guastello, S. (20I4). Patient-centered Communication Strategies: Shifting from Communicating to Patients to Communicating with them. [Online] available at http://nwhc.net/ckfinder/userfiles/files/Dorland\%2 OHealth-CaseArticle.pdf. Accessed 4 June, 2018.

Hashim,M.J.(2017). Patient-centred communication: Basic skills. American Family Physician, 95(I), 2934

Hellın T. (2002). The Physician-Patient Relationship: Recent Developments and Changes. Haemophilia, 8, pp.450-454.

Hochman, O., Itzhak, B., Mankuta, D and Vinker, S. (2008). The relationship between good communication skills on the part of the physician and patient satisfaction in a military setting. Military Medicine, 17 (3), 878-88I

Ibrahim, S., Ugwa, A., Garba, I., Yakasai, Zakari, M. and Abubakar, M. (20I5). Patients' Preference for Doctor's Gender in North-western Nigeria. Tropical Journal of Obstetrics and Gynaecology, 32(2) [Online] Available at https://www.ajol.info/index.php/tjog/article/view/l 25094. [Accessed 23 January, 2019].

ledema, R. and Manidis, M. 2013. Patient-clinician Communication: An Overview of Relevant Research and Policy Literatures. Sydney. Australian Commission on Safety and Quality in Health Care and UTS Centre for Health Communication, pp.I-208 [Online]. Available at https://www.safetyandquality.gov.au/wpcontent/uploads/2012/02/Final-Report-PatientClinician-Communication-Literature-Review-Feb2013.pdf. Accessed 22 January, 2019].

Jalil, A., Zakar, R., Zakar, M.Z. and Fischer, F. (2017). Patient satisfaction with doctor-patient interactions: A mixed methods study among diabetes mellitus patients in Pakistan. BMC Health Services Research, I7, I55. Doi: I0.। I86/s/I29/30I 7-2094-6

Juran J, Gryna F. 1993. Quality planning and analysis: From Product Development through Use. New York, NY: McGraw-Hill. [Online]. Available at https://www.amazon.com/Quality-Planning-

Analysis-Development-McgrawHill/dp/007033 I839. [Accessed I 2 January, 2019]. 
Kapa, R. Sooriakumaran, P. (2007). The Evolution of The Doctor-Patient Relationship. International Journal of Surgery. 5, pp.57-65.

Kaiser, H. (1970). A second generation Little Jiffy. Psychometrika, 35, 40I-4I5.

Kaiser, H, (1974). An index of factorial simplicity. Psychometrika, 39, 31-36.

Keller, A. C., Bergman, M. M.,Heinzmann, C.,Todorov, A.,Weber, H.,\&Heberer, M. (20l4). The relationship between hospital patients' ratings of quality of care and communication. International Journal for Quality in Health Care, 26(I), 26-33.

Kelley, J.M, Kraft-Todd, G, Schapira, L, Kossowsky, J, Riess, H. (2014). The Influence of the PatientClinician Relationship on Healthcare Outcomes: A Systematic Review and Meta-Analysis of Randomized Controlled Trials. PLoS One 9(4). [Online] available at https://journals.plos.org/plosone/article?id = 10.137 I/journal.pone.0094207. [Accessed 8 February, 2019.]

Kilbridge, K. L., Fraser, G., Krahn, M., Nelson, E. M., Conaway, M., Bashore, R., Wolf, A., Barry, M. J., Gong, D. A., Nease, Jr. R. F., \& Connors A. F. (2009). Lack of Comprehension of Common Prostate Cancer Terms in an Underserved Population. American Society of Clinical Oncology, 27(I2), pp.2015-202I.

King A, \& Hoppe, R. (20/3). Best Practice for Patient-Centered Communication: A Narrative Review. Journal of Graduate Medical Education. 5(3), pp.385-393.

Levinson, W., Lesser, C.S. and Epstein, R.M. (2010). Developing physician communication skills for patient-centred care. Health affairs, 29(7), 13101318

Maraña, M. (20I0). Culture and Development Evolution and Prospects. United Nations Scientific Education and Cultural Organization. [Online] Retrieved

fromhttp://www.unesco.or.kr/eng/front/program mes/links/6_CultureandDevelopment.pdf.

[Accessed I2 December, 2018].

Mohammed A, Idowu I, Kuyinu Y. Structure of Primary Health Care: Lessons from a Rural Area in South-West Nigeria. Nigerian Journal of Clinical Medicine. (20I0), 3(I), pp.7-24.

Moore $P$, Vargas A, Núñez $S$, \&Macchiavello $S$. (20II). A Study of Hospital Complaints and the Role of Doctor-Patient Communication. Korean Journal of Medical Education. RevistaMédica de Chile, 139 (7), pp.880-5.

Morris M.A, Clayman M.L, Peters KJ, Leppin AL, LeBlan. (20I5). Patient-centered Communication Strategies for Patients with Aphasia: Discrepancies between What Patients Want and What Physicians Do. Disability Health Journal. 8(2), pp.208-2I5.

Murante, A, M. 2010. Patient Satisfaction: A Strategic Tool for Health Services Management. [Online] Available at http://www.phdmanagement.sssup.it/documenti/a warded/murante_thesis.pdf. [Accessed December I2, 20I8].

Murgic,L. Hébert,C.P., Sovic, S. and Pavlekovic, G. (20I5). Paternalism and Autonomy: Views of Patients and Providers in a Transitional (PostCommunist) Country. Bio Medical Central Medical Ethics, 16, p.65

Naughton, C. (2018). Patient-centred communication. Pharmacy, 6, 18

Nolen, H.A., Moore, J.X., Rodgers, J.B., Wang, H.E. and Walter, L.A (20I6). Patient preference for physician gender in the Emergency Department. Yale Journal of Biology and Medicine, 89 (2), I3I142.

Ogaji, D., Giles, S., Daker-White, and Bower, P. (2016). Findings and Predictors of PatientReported Experience of Primary Healthcare in Nigeria. Journal of Patient Experience, 3(3): pp.69-80.

Paternotte, E., Dulmen, S,V., Lee, N.V., Scherphier, A.J.J.A. and Scheele, F. (20I5). Factors influencing intercultural doctor-patient communication: A realist review. Patient Education and Counseling, 98(4), 420-445

Pargament, K. I., and Saunders, S. M. (20070. Introduction to the Special Issue of Spirituality and Psychotherapy. Journal of Clinical Psychology. 63 (10), pp.903-907.

Peck, B.M. (20II). Age related differences in doctorpatient interaction and patient satisfaction. Current Gerontology and Geriatrics Research, 201I, $137492 . \quad$ Doi: htpps://doi.org//0.I I55/20 I I/I 7492

Powell, L. (200I). Patient Satisfaction Surveys for Critical Access Hospitals. An Initiative of the National Rural Health Resource Center with Partial Funding from the Federal Office of Rural Health Policy, Health Resources and Services Administration [online]. Available at: file://C:/Users/hp/AppData/Local/Temp/Assessing PatientSatisfaction.pdf (Accessed 17 July, 2019).

Rashid, A. and Al-Balushi, A. (2014). Patient satisfaction survey as a tool towards quality improvement. Oman Medical Journal. 29(I), pp.37.

Rezaei, F. and Askari, H.A. (20l4). Checking the relationship between physicians' communication skills and outpatients' satisfaction in the clinics of 
Isfahan Al-zahra(s) Hospital in 20II. Journal of Education and Health Promotion, 3, 105

Roter, D. (2010). Models of Doctor-Patient Relationship. John Hopkins Bloomberg School of health Publication. [Online]. Available at http://ocw.jhsph.edu/courses/ISBTII/PDFs/Session 2 Iroterinteraction2010.pdf. Accessed 3 February, 2019].

Taylor, P.S., Nicolle, C. and Maguire, M. (20/3). Cross Cultural Barriers in Health Care. Nursing Standards, 27 (3I), pp.35-43.

Thomas, B.J., Jayakumar, D.S. and Suganya, G. (20I7). Effect of patient-centredness on health service experience: Mediation of patient satisfaction. British Journal of Healthcare Management, 23(I 2), 59|-600

Thompson, G.A. and Whiffen, L.H. (20I8). Can physicians demonstrate high quality care using paternalistic practice? A case study of paternalism in Latino physician-patient interactions. Qualitative Health Research, 00(0), I- 13

Thurstone, L. L. (1947). Multiple factor analysis. Chicago: University of Chicago Press.

Travaline, M. Ruchinskas, R \&D’Alonzo, G. 2005. Patient-physician Communication: Why and How.Journal of the American Osteopathic Association, 105, pp. I3-18.

Verlinde, E., Laender, N.D., Maesschalck, S.D. Deveugele, M. and Willems, S. (20/2). The social gradient in doctor-patient communication.
International Journal for Equity in Health, II, 12. Doi: I0. I |86/ | 475-9276-I I-I 2

Watkins, M. W. (2000). Monte Carlo PCA for parallel analysis [computer software]. State College, PA: Ed \& Psych Associates.

Wilkins, S. 2014. Paternalist vs. Patient-Centered Approach to Patient Engagement. [Online] available

http://www.healthworkscollective.com/stevewilkins/I 5 I87I/paternalist-versus-patientcentered-approach-patient-engagement. Accessed 12 December 2018].

Willems, S., De Maesschack, S., Deveugele, M., Derese, A. and De Maeseneer, J. 92005). Socioeconomic status of the patient and doctorpatient communication. Patient Education and Counseling, 56 (2), |9-|46

Wimmer, R. and Dominick, J. (2003). Mass media research: An introduction, 7th edition. Belmont, California: Wadsworth.

Wynia, M and Matiasek, M. (2006). Promising Practices for Patient-Centered Communication with Vulnerable Populations: Examples from Eight Hospitals. [Online]. Available at http://www.geneticcounselingtoolkit.com/pdf_files /promisingpracticespatientcenteredcommunicatio n.pdf. Accessed I 2 December 2018].

Zadeh, E. and Mozaffari, A. 2014. The Impact of Satellite TV Channels on Lifestyle Changes for Women in Iran. International Journal of Business and Social Science, 5 (3), pp.|26-|3|. 